\title{
GUI INTERFACE TO PERFORM FUNCTIONAL CALCULATION OF THE SHALE SHAKER, CLEANING ELEMENT OF THE SYSTEM OF DRILLING MUD
}

\author{
Maria Georgeta POPESCU ${ }^{1}$ \\ Georgeta Claudia NICULAE ${ }^{2}$ \\ loana Gabriela STAN ${ }^{3}$ \\ Iuliana Veronica GHETIU ${ }^{4}$
}

${ }^{1}$ Assoc. Prof. U.P.G. Ploiesti, FET Departament

${ }^{2}$ Lecturer, PhD U.P.G. Ploiesti, INM Department

${ }^{3}$ Assist lecturer, PhD U.P.G. Ploiesti, FET Departament

${ }^{4}$ Assist lecturer, PhD, U.P.G. Ploiesti, FET Departament

Abstract: This paper describes the execution and usage methodology offered by MATLAB facilities, by designing a GUI graphical interface used to calculate the dimensional elements of $V$ belt transmission and the perturbing force necessary to achieve the vibratory motion. The paper also covers all stages of spring calculation, as well as cinematic calculation notions concerning the perturbing system.

Keywords: GUI graphical interface, shale shaker, drilling mud

The types and quantities of cuttings present in drilling mud system have major role in the fluid's properties as: density, viscosity, filter cake quality and filtration control. Cuttings removal is one of the most important aspects of mud system control, because it has a direct bearing on drilling efficiency.

Cuttings removal on the rig is accomplished by one or more of the following basic methods:
- screening;

- hydrocycloning;

- centrifugation;

- gravitational settling.

A diagram of a typical mud circulating system, including various solids-control devices, is shown in figure 1:

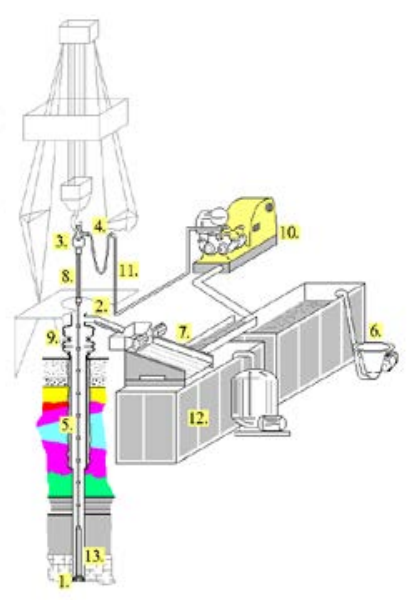

Fig. 1. Drilling fluid circulating system

1 -drill bit ; 2 - flow line; 3 - crown block; 4 - vibrating hose; 5 - drill pipe; 6 - equipment for drill mud preparation; 7 - equipment for drill mud separation of mud pit; 8 - Kelly; 9 - BOP's equipment; 10 - mud pump; 11 - standpipe; 12 - mud tank; 13 - drill collar.

The most important solids-control devices are shale shakers .
A shale shaker is a vibrating screen separator used to remove drill cuttings from the mud. The basic shale shakers types used are: 
"Mircea cel Batran" Naval Academy Scientific Bulletin, Volume XIX - 2016 - Issue 2

The journal is indexed in: PROQUEST / DOAJ / Crossref / EBSCOhost / INDEX COPERNICUS / DRJI / OAJI I JOURNAL INDEX I I2OR / SCIENCE LIBRARY INDEX / Google Scholar / Academic Keys/ ROAD Open Access I Academic Resources / Scientific Indexing Services / SCIPIO / JIFACTOR

- Circular-motion shaker

- Elliptical-motion shaker

- $\quad$ Liner-motion shaker.

Shale shaker performance is affected by the type of the motion, stroke length of the deck and the rotary speed of the motor.

Shale shakers kave a back tank to receive mud from the flowline. The mud flows over a weir and is distributed to the screening surface. The screen is placed over a basket that has a vibratory motion. The basket is mounted on helical springs. Below the basket is used a collection bed to channel the screen underflow to the active system.

Shale shakers are the most important and easiest-to-use solids-removal equipment. A diagram of a typical shale shaker is shown in figure 2 .

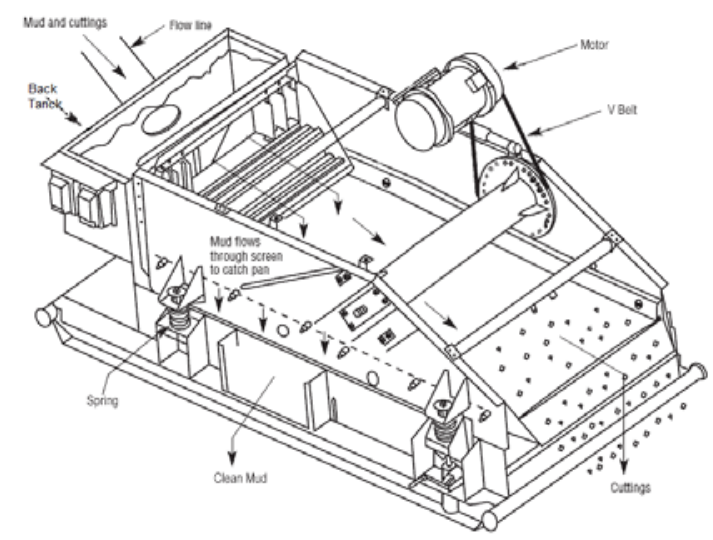

Figure 2 Shale shaker's diagram

Figure 2 presents the active elements of a shale shaker: electric motor, transmission V-belts, shaft vibrator that transmits vibrations to the hopper mounted on helical springs.

The study of this paper is based on sizing V-belt transmission.

Initial data for design are:

- computing power to the drive shaft

- nominal power transmitted by a $\mathrm{V}$-belt

- RPM of V-belt's running wheel

- RPM of V-belt's driven wheel

- driven wheel's diameter

- efficiency of the transmission

- functional ratio of transmission

The graphical interface build in MatlabGUI(figure 1 ) is using predefined objects available in Matlab, such as:

- 5 objects type Edit Text

- 24 objects type Static text

- 1 object type Push Button

- 1 object typePopup-ul menu
- length ratio

- Winding ratio

- V-belts no. ratio

Shall be calculated:

- transmission ratio:

$$
i=\frac{n_{1}}{n_{2}}
$$

- diameter drive gear:

$$
D_{p 2}=i \times D_{p 1}
$$

- the average diameter pulley:

$$
D_{p n}=\frac{D_{p 1}+D_{p 2}}{2}
$$

- distance between axles pulleys

$$
\begin{gathered}
A=0,25 \times L_{p}-0,393 \cdot\left(D_{p 1}+D_{p 2}\right) \\
-\sqrt{\left[0,25 \times L_{p}-0,393 \times\left(D_{p 1}+D_{p 2}\right)\right]^{2}} \\
-0,125 \cdot\left(D_{p 2}+D_{p 1}\right)^{2} \\
\text { the angle of the branches V- } \\
\text { belt: } \gamma=2 \cdot \arcsin \frac{D_{p 2}-D_{p 1}}{2 \cdot A}
\end{gathered}
$$

- $\quad$ winding wheel angle than $\mathrm{V}$-belt

$\beta=180^{\circ}-\gamma$

- V-belt length:

$$
L_{p}=2 \cdot A+\pi \cdot D_{p n}+\frac{\left(D_{p 2}-D_{p 1}\right)^{2}}{4 \cdot A}
$$

- peripheral velocity of the $\mathrm{V}$ belt: $v=\frac{\pi \cdot D_{p 1} \cdot n_{11}}{60 \cdot 1000}$

- $\quad$ finalnumber of V-belts

$$
Z=\frac{P_{c} \times c_{f}}{c_{l} \times c_{b} \times c_{z} \times P_{0}}
$$


"Mircea cel Batran" Naval Academy Scientific Bulletin, Volume XIX - 2016 - Issue 2 The journal is indexed in: PROQUEST / DOAJ / Crossref / EBSCOhost / INDEX COPERNICUS / DRJI / OAJI I JOURNAL INDEX I I2OR / SCIENCE LIBRARY INDEX / Google Scholar / Academic Keys/ ROAD Open Access I Academic Resources / Scientific Indexing Services / SCIPIO / JIFACTOR

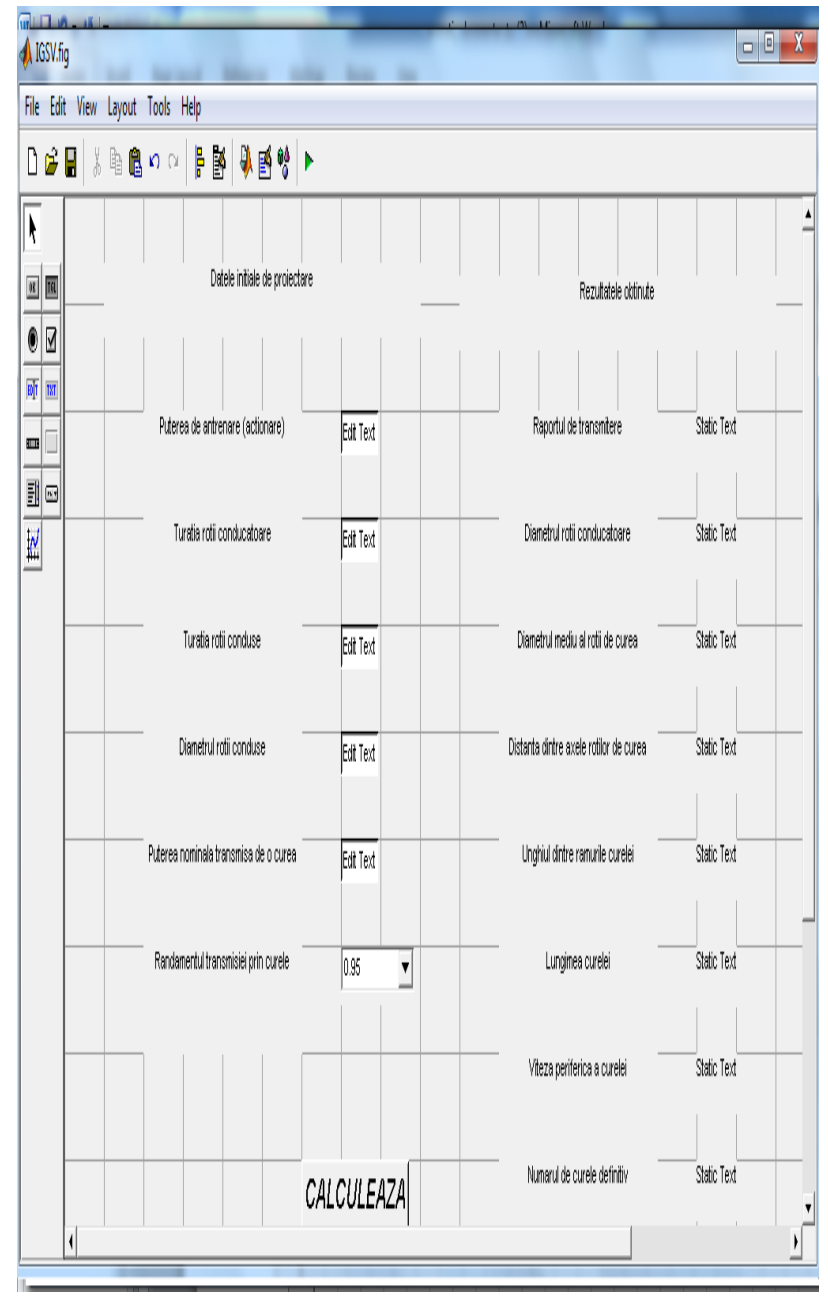

Figure 1 Graphical Interface built in Matlab

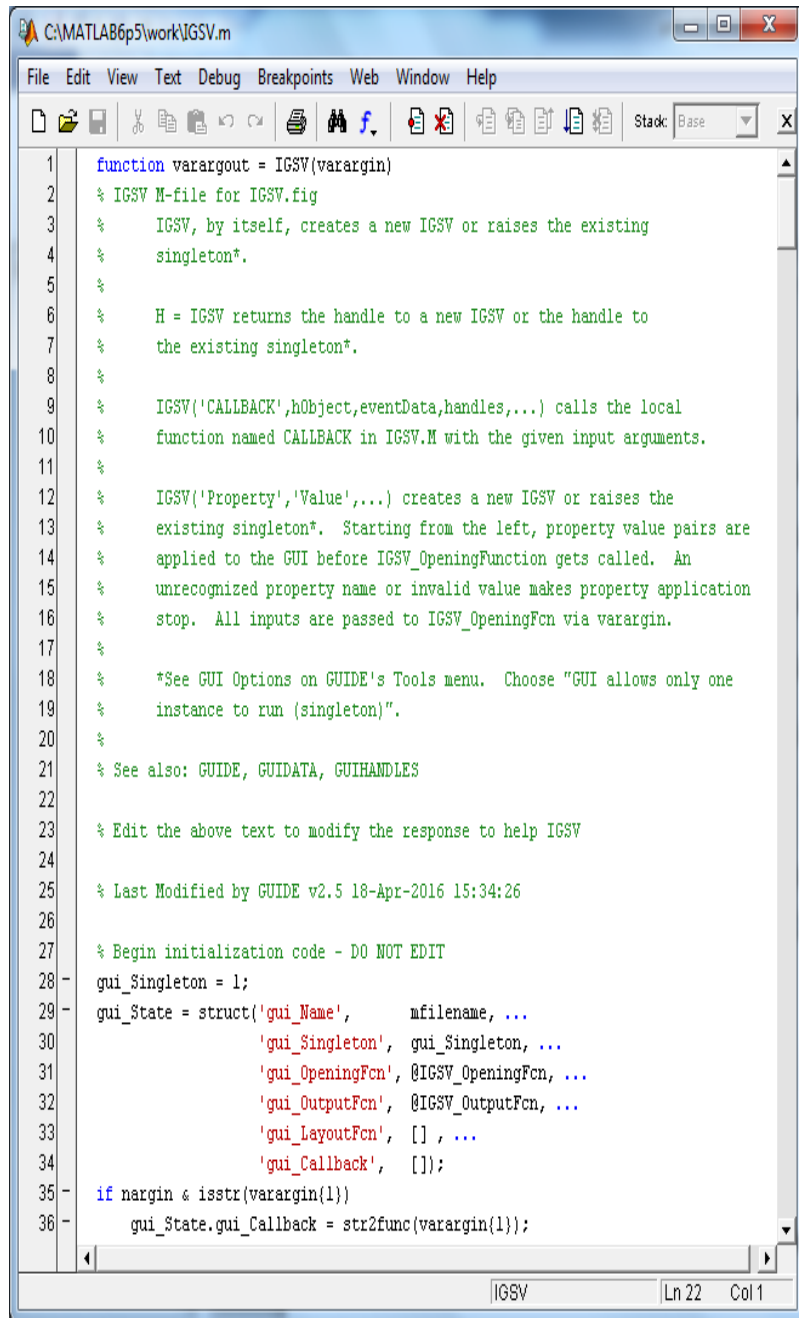

\section{Figure 2 IGSV.m (Source Programm)}

GUI, once configured and saved generates two filesIGSV.m (fig 2)and IGSV.fig (fig 3). In the IGSV.m file will configure properties of all objects built in file/GSV.fig.

Presented GUI is used to calculate the dimensional elements of $\mathrm{V}$ belt transmission, according to the algorithm presented in this article. The result is displayed by running the file IGSV.m and then after opening IGSV.fig. will obtain window from Figure 4. Here are entered from the keyboard initial design data. 
"Mircea cel Batran" Naval Academy Scientific Bulletin, Volume XIX - 2016 - Issue 2 The journal is indexed in: PROQUEST I DOAJ / Crossref / EBSCOhost / INDEX COPERNICUS / DRJI / OAJI I JOURNAL INDEX I I2OR / SCIENCE LIBRARY INDEX / Google Scholar / Academic Keys/ ROAD Open Access I Academic Resources / Scientific Indexing Services / SCIPIO / JIFACTOR

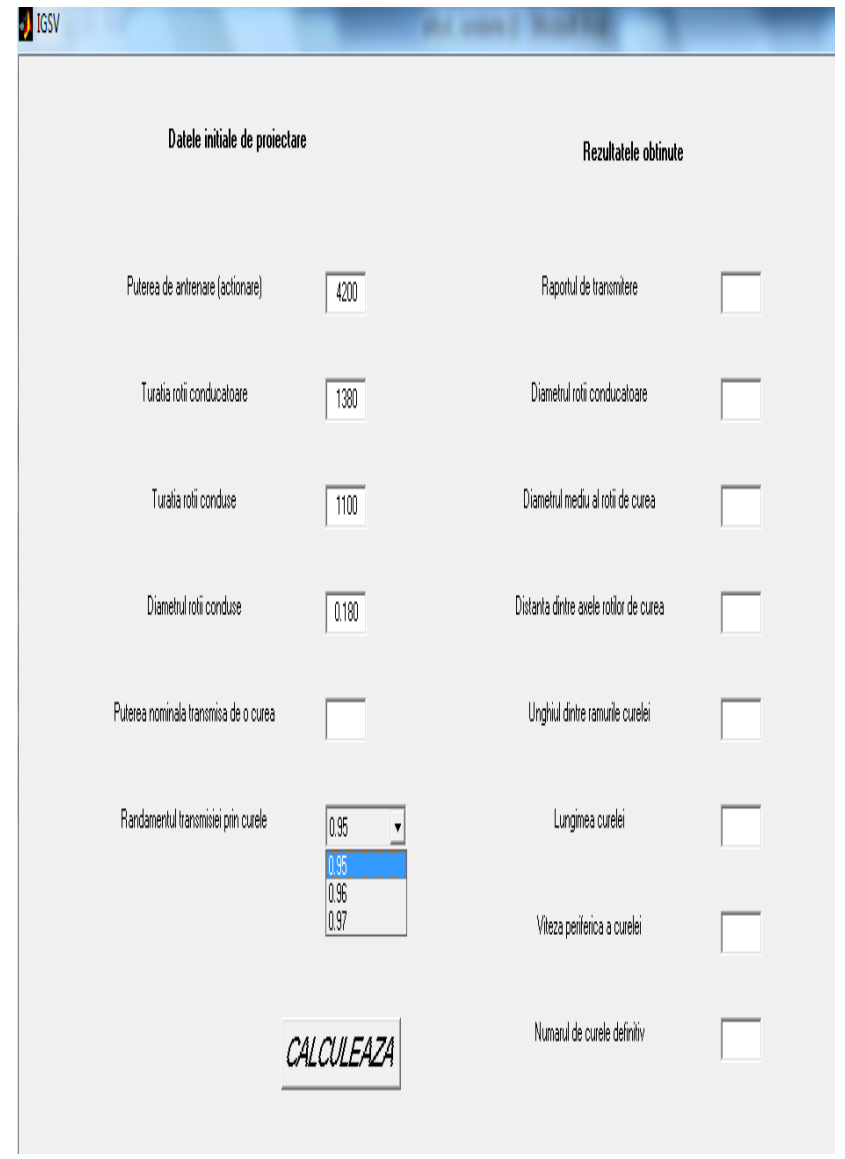

Figure 3.IGSV.fig generated from the GUI (Initial Data Input)

The elements of $\mathrm{V}$-belt transmission are calculated after pressing button CALCULEAZA, and values will be returned as shown in Fig 4.

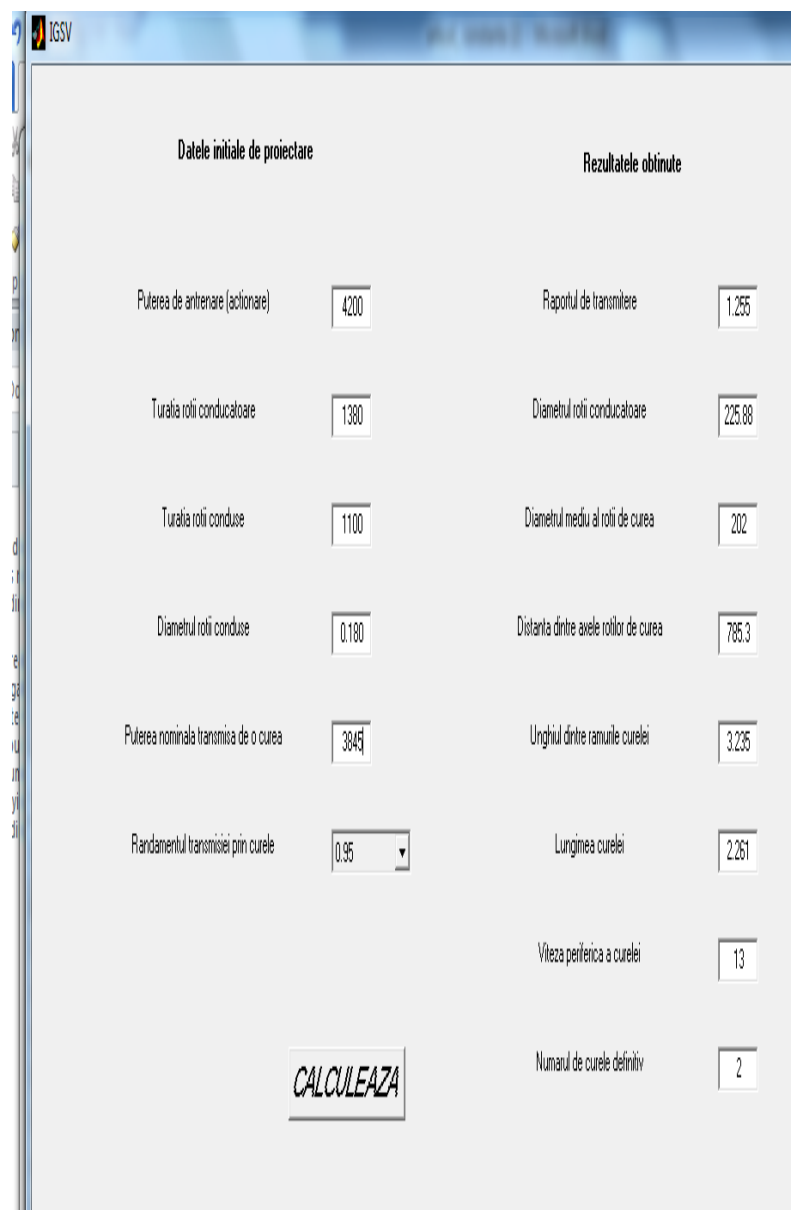

Figure 4.IGSV.fig generated from the GUI (Results Obtained)

\section{CONCLUSION}

Using the facilities offered by this programming environment are useful and functional helping for calculation of shale shaker's parameters. This article is the first stage of calculation, the purpose being to achieve a graphical interface that covers the calculation of all components of the cleaning system of drilling mud by creating multiple windows work.

\section{BIBLIOGRAPHY}

[1] Popescu, M., Fluide de foraj şi cimenturi de sondă, Editura Universităţii din Ploieşti, 2002

[2] Popovici, Al., Niculae, C., s.a., Calculul şi construcţia utilajului pentru forajul sondelor de petrol, Editura Universităţii din Ploieşti, 2005 